\title{
Swallowing impairment in older adults: association with sensorimotor peripheral nerve function from the Health, Aging and Body Composition study
}

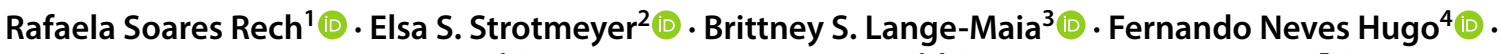

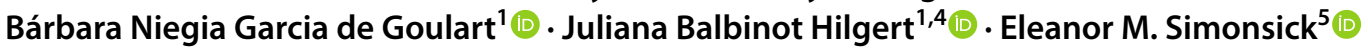

Received: 2 December 2019 / Accepted: 21 February 2020 / Published online: 10 April 2020

(c) This is a U.S. Government work and not under copyright protection in the US; foreign copyright protection may apply 2020

\begin{abstract}
Background The purpose of this study was to examine whether impairments in sensorimotor peripheral nerve function are associated with a higher likelihood of swallowing impairment in older adults.

Methods Health, Aging and Body Composition participants ( $n=607$, age $=75.8 \pm 2.7$ years, $55.8 \%$ women, $32.3 \%$ black $)$ underwent peripheral nerve testing at Year 4 and 11 with swallowing difficulty assessed at Year 4 and 15 . Nerve conduction amplitude and velocity were measured at the peroneal motor nerve. Sensory nerve function was assessed with the vibration detection threshold and monofilament $(1.4-\mathrm{g} / 10-\mathrm{g})$ testing at the big toe. Symptoms of lower extremity peripheral neuropathy and difficulty swallowing were collected by self-report. Data analysis was performed using a hierarchical approach. Odds ratios (ORs) were estimated using non-conditional logistic regression.

Results At Year 15108 (17.8\%) participants had swallowing impairments. In fully adjusted models, the peripheral nerve impairments associated with swallowing impairment were numbness (OR 4.67; 95\% CI 2.24-9.75) and poor motor nerve conduction velocity (OR 2.26; 95\% CI 1.08-4.70). Other peripheral nerve impairments were not related to swallowing.

Conclusions The association between slow motor nerve conduction velocity and numbness and a higher likelihood of swallowing difficulties a decade later in our prospective study identifies an important area for further investigation in older adults.
\end{abstract}

Keywords Swallowing $\cdot$ Swallowing disorders $\cdot$ Deglutition disorders $\cdot$ Swallowing difficulties $\cdot$ Autonomic nervous system $\cdot$ Peripheral nerves $\cdot$ Older adults

Eleanor M. Simonsick

simonsickel@grc.nia.nih.gov

1 Graduate Studies Program in Epidemiology, Faculty of Medicine, Universidade Federal Do Rio Grande Do Sul, Porto Alegre, Brazil

2 Department of Epidemiology, Graduate School of Public Health, University of Pittsburgh, Pittsburgh, USA

3 Department Preventive Medicine, Rush University Medical Center, Chicago, IL, USA

4 Graduate Studies Program in Dentistry, Faculty of Dentistry, Universidade Federal Do Rio Grande Do Sul, Porto Alegre, Brazil

5 Intramural Research Program, National Institute on Aging, Harbor Hospital, 3001 S. Hanover Street, Baltimore, MD 21225, USA

\section{Introduction}

Swallowing is a complex and dynamic sensorimotor activity involving twenty-six pairs of muscles and five cranial nerves [1]. The central neural control of swallowing is characterized as "multidimensional in nature" because it involves all levels of the nervous system $[2,3]$. Swallowing plays a vital role in the daily lives of all individuals, transporting nutrients and necessary energy from the oral cavity to the stomach [4].

It is well-documented that some neurological pathologies (stroke, dementia, Parkinson's disease and multiple sclerosis) as well as head and neck cancer, cervical spine surgery, traumatic brain injury, and chronic obstructive pulmonary disease are associated with swallowing impairments [5]. Less is known about how swallowing ability changes with age in the absence of specific diseases [6,7]. The main consequences associated with alterations in swallowing are increased dehydration, 
malnutrition, depression, frailty, aspiration pneumonia, longer hospital stays and early mortality $[8,9]$.

The peripheral nervous system is composed of two distinct divisions, sensorimotor and autonomic. Both divisions play integral roles in providing information to the central nervous system. Peripheral nervous system aging is characterized by a phenomenon known as "selective vulnerability" in which locally specific structural and functional changes can vastly affect some groups of neurons while leaving others relatively intact [10]. The impairments are often present with diabetes or specific neurological conditions; however, age-related impairments and declines are present even in the absence of any pathologic conditions [11]. It is known that the peripheral nervous system responds to stimuli, and controls functions of the body, the swallowing process included. Therefore, agerelated changes in swallowing, as a process that depends on sensory information and autonomic inputs, could be affected by age-related sensorimotor peripheral nerve impairment.

To date, no studies with sufficiently long follow-up have been conducted on the likelihood of swallowing complaints and associated factors. Also, few studies include measures of both the peripheral nervous system and swallowing complaints in community-dwelling older persons. Therefore, our hypothesis was that initial impairments in sensorimotor peripheral nerve function in older adults would be associated with a higher likelihood of swallowing impairment a decade later.

\section{Methods}

\section{Participants}

Participants were from the Health, Aging and Body Composition Study (Health ABC) with data from the Year 4 and 11 clinic visits and Year 15 quarterly phone survey used in the analyses. Health $\mathrm{ABC}$ is a longitudinal cohort study focused on risk factors for the decline in function in initially healthier older black and white men and women. Participants were recruited in 1997-1998 by mail from specified zip codes surrounding Memphis, Tennessee, and Pittsburgh, Pennsylvania, followed by a telephone eligibility screen. All participants were eligible Medicare beneficiaries, the US federal health insurance program for those $\geq 65$ years. Whites were recruited from a random sample of Medicare beneficiaries. Blacks were recruited from Medicare beneficiaries and all age-eligible residents in these areas to achieve approximate equal numbers of White and Black study participants. The eligibility criteria established were: no self-reported difficulty in walking $1 / 4$ mile, climbing ten steps, or performing any basic activity of daily living; no life-threatening cancers; and plans to remain in the study area for at least three years. At baseline, the sample consisted of 3075 communitydwelling older persons, men $(48.4 \% ; n=1488)$ and women
(51.6\%; $n=1587)$ aged 70 -to-79 years. All participants provided written informed consent before participating. Protocols were approved by institutional review boards at the University of Pittsburgh and University of Tennessee Health Science Center [12]. The analytic sample included 607 participants with all relevant data from Years 4, 11 and 15.

\section{Sensorimotor Nerve Function Exam}

Sensorimotor peripheral nerve function impairment data were from the following peripheral neuropathy exams: vibration perception threshold, peroneal motor nerve conduction and monofilament testing. All exams were performed by trained examiners at both study sites. To perform the exams, participants' right foot was heated (unless contraindicated, in which case testing was performed on the left side) to $30^{\circ} \mathrm{C}$.

Peroneal motor nerve conduction was examined using the NeuroMax 8 (XLTEK, Oakville, Ontario, Canada), which measured responses of the extensor digotorum brevis muscle with stimulation at the popliteal fossa. Motor nerve conduction velocity (meters/second) and amplitude (millivolts) were recorded, with standardization of testing by a board-certified neurologist as previously described [13]. Vibration detection threshold (micrometers) was measured using a VSA-3000 Vibratory Sensory Analyzer (Medoc, Durham, North Carolina) at the bottom of the great toe. Touch sensitivity was assessed using a standard 10-g and light touch 1.4-g monofilament (North Coast Medical, Inc) at the dorsum of the great toe. The entire clinic exam was performed in the same order for all participants. In addition to clinical exams, self-reported symptoms of peripheral neuropathy were investigated: numbness, "asleep feeling", prickly feeling or tingling; sudden stabbing, burning, or deep aches; or an open persistent sore or gangrene on either the foot or leg in the past 12 months. Poor motor nerve amplitude and poor conduction velocity were defined as $<1 \mathrm{mV}$ and $<40 \mathrm{~m} / \mathrm{s}$, respectively [14]. Poor vibration threshold was defined as $>130 \mu \mathrm{m}$, indicating that the participant was unable to detect the maximum vibration. For purposes of analysis and follow up over the years, we created the clinical predictor variables by comparing results from Year 4 and 11. Amplitude, velocity and vibration were categorized as normal, if normal at Year 4 and 11, or altered if there was a change from normal to impaired in at least one of the categories. The few cases that showed improvement in Year 11 were also considered as altered. Self-reported variables were also categorized in this way and were considered altered if there was a change from normal to impaired in at least one category. 


\section{Swallowing impairment}

The outcome studied was swallowing impairment, defined as a yes/no response from a quarterly phone interview conducted in Year 15: "Since we last spoke to you, have you had any difficulty swallowing?". This variable was self-reported both by the individual or by a proxy. If in at least one quarter of Year 15 the individual reported difficulty in swallowing, this was considered a positive case for swallowing impairment, dichotomized as normal swallowing or swallowing impairment. At Year 4 (baseline for this study), only 4 individuals reported difficulties in swallowing. These individuals were excluded from the analysis so that the follow-up was performed using persons without swallowing impairment.

\section{Covariates}

Age (in years), sex (male; female), race (white or black), and clinical site (Memphis; Pittsburgh) were included as demographic characteristics. Education (high school (HS) diploma; HS diploma/equivalent or above) an income $(>\$ 50,000 ; \leq \$ 50,000)$ were include as socioeconomic variables. Lifestyle factors assessed via self-report included: marital status (single/divorced/widowed; married/living as partnered), smoking history (never/former/current; in 1999/2000), drinking status (never/former/current; in 1999/2000), and physical activity (kilocalories/week walking and stair climbing, in 2000/2001). Oral health status was investigated from a sub study conducted in 1999-2000 from the following variables: number of teeth (none; $1-20 ;+20$ ), the total number of functional teeth (in units) and wear dentures (yes; no). Factors which may potentially influence sensorimotor function (diabetes, cardiovascular function (heart attack; angina; hypertension) and stroke: yes; no) or swallowing impairment (stroke; pneumonia; cancer and any fracture: yes; no), were considered as possible self-reported covariates and were measured from Year 1 to Year 4 clinic visit considering yes for the positive answer in at least one of the years for each disease, respectively. In addition, some health condition variables were collected via self-report including health status (fair and poor; good) and self-report depression scale depression (yes; no) [15] or observed performance such as the Health ABC summary performance score (combining usual walk, narrow walk, chair stand, and standing balance performance ratios) [16].

\section{Statistical Methods}

In studies where determinants of disease are sought, it is suggested that the complex hierarchical inter-relationships between these determinants are best managed using conceptual frameworks. Thus, data analysis was performed using a hierarchical approach (Fig. 1). The variables were grouped into a hierarchy of categories, ranging from distal to proximate determinants, according to the hierarchical methodology proposed by Victora et al. [17]. The model consists of five blocks: block 1: demographic and socioeconomic variables; block 2: behavioral variables; block 3: oral health status; block 4: health status; and block 5: sensorimotor peripheral nerve function impairments. The first block of analysis conceptualizes demographic and socioeconomic variables. Block 2 included variables related to behavior and personal characteristics. Oral health status was addressed in the third block. The fourth block of analysis consisted of health status (chronic, neurological and other diseases) and Health ABC performance score and finally block 5, which encompasses sensorimotor peripheral nerve function impairments. This framework was used to increase the likelihood that no relevant variable was left unadjusted for because it considers theoretical and statistical criteria to build the analysis models.

Descriptive statistics were calculated and stratified by swallowing difficulty $(y / n)$, with the difference of the means calculated using Student's $t$ test and the difference of the medians by non-parametric testing using $\mathrm{U}$ Wilcoxon-Mann-Whitney. The chi-squared test was used to assess univariate associations, and when test assumptions were violated, the Fisher's exact test was used. Odds ratios (ORs) were estimated using non-conditional logistic regression. The hierarchical approach consisted of the use of univariate logistic regression models to estimate the relationships between studied variables and the outcome. Multivariate logistic regressions were then performed within each block. Variables were retained in subsequent levels if $p<0.10$ after adjusting for confounders in their own block and those maintained from previous ones. Ultimately, only variables with $p<0.10$ in previous models were included in the final, fully adjusted model. In this model, the association between the studied variables and the outcome was estimated using ORs and respective 95\% confidence intervals (CIs). The presence of multicollinearity was evaluated by means of the Variance Inflation Factor estimates, noting that the cutoff points are good (close to 1 ) indicating that the variables are not collinear. Sensitivity analysis excluding persons who developed stroke, diabetes or hypertension over the follow-up period was performed using the same approach. All analyses demonstrate the same direction and significance of the observed 
Fig. 1 Theoretical framework for the investigation of risk factors for swallowing difficulties in hierarchical blocks

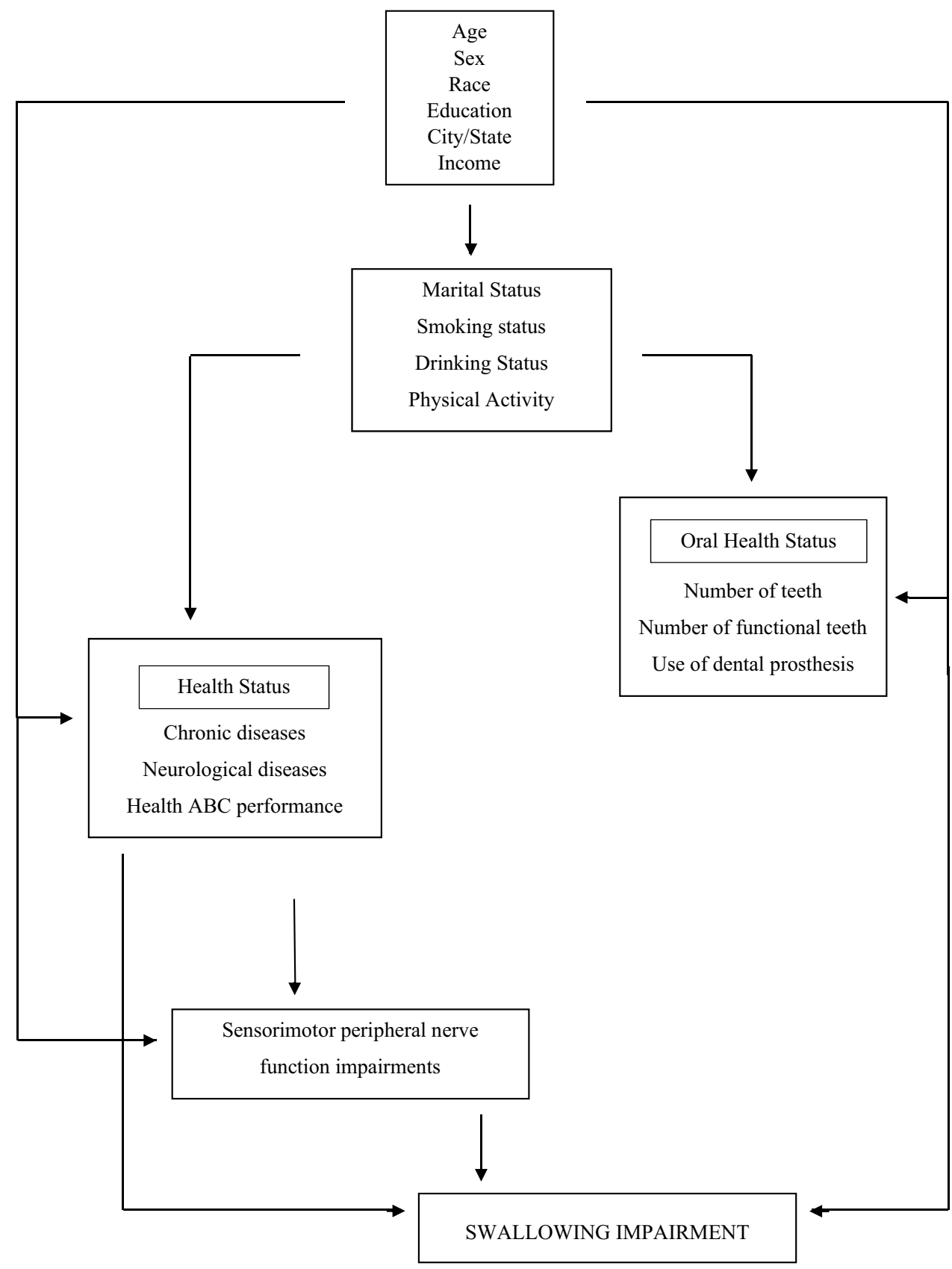

associations. All statistical analyses were performed using the SPSS version 21.0 (SPSS Inc., Chicago, IL).

\section{Results}

At Year 15, 17.8\% ( $n=108)$ of participants had swallowing impairments. Table 1 shows the sample characteristics. Characteristics associated with having swallowing impairments included, Memphis site, fair/poor health status, stroke, hypertension, presence of depressive symptoms, numbness, pain, and poor nerve conduction velocity. It stands out among the descriptive results that those with swallowing impairment have better nerve function cross-sectionally.

In the regression analysis, income $(>\$ 50,000)$ (OR 0.62 ; 95\%CI 0.40-0.97) and sex (male) (OR 0.64; 95\%CI $0.42-0.97$ ) remained significant in block 1 . In block 2 , with adjustment for block 1 variables, none of the block 2 variables remained significant. The same is true in the adjusted analysis of block 3 by block 1 . The following variables in block 4 were significantly associated with the outcome, adjusting for block 1 variables: health status (fair 
and poor) (OR 2.51; 95\%CI 1.69-3.73), stroke (OR 3.73; 95\% CI 1.52-9.16) and presence of depression symptoms (OR 1.47; 95\% CI 1.05-2.07). Hypertension (OR 0.55; 95\% CI 0.29-1.05) and heart attack/angina (OR 2.10; 95\% CI $0.88-5.02)$ were also retained in subsequent levels $(p<0.10)$.

In the final model, the predictor variables that remained significantly associated with the outcome of swallowing impairment were numbness (OR 4.67; 95\%CI 2.24-9.75) and poor nerve conduction velocity (OR 2.26; 95\%CI 1.08-4.70). (Table 2).

\section{Discussion}

The results indicate that initial symptoms and clinical alterations of sensorimotor peripheral nerve function are associated with the development of swallowing impairment a decade later in older adults. We evaluated subclinical selfreported and objective impairments suggestive of peripheral neuropathy, but often undiagnosed in older adults [10]. This study highlights these important clinical and subclinical markers of swallowing impairment in community-dwelling older adults. Results suggest that markers of swallowing impairment may be useful in the evaluation of older persons who do not present with incapacitating diseases such as those already described in the literature that cause swallowing problems. Swallowing is critical to biological and biochemical functions [18]. Novel and early risk factors for any initial change in swallowing are important since the consequences of this change can be serious. The greatest strength of this study is its degree of innovation since as far as we know, no other study has published prospective data on the development of difficulty in swallowing in initially healthy community-dwelling older persons with adjustment for possible additional factors related to swallowing impairment in aging.

Although we examined nerve function in the legs and feet, it is understood that these measures reflect central control of bodily functions with poor performance indicative of impairment that are generalizable to commands of swallowing. One possible explanation for the observed associations is that changes in the central and peripheral nervous systems that are operating on swallowing function were captured indirectly by measuring nerve amplitude, conduction velocity and vibration threshold $[4,19,20]$. There exists an integration and overlap of the oral neuronal pathways with the subsequent pharyngeal route [21]. Changes in the system that provides feedback and controls all necessary steps may disrupt the entire process. Older people who have slow motor velocity will likely experience delay in the reflexes and commands necessary for all phases to occur harmoniously. Our findings are supported by the underlying neurobiology of swallowing.
In addition to nerve conduction velocity, numbness emerged as an important symptom predicting swallowing difficulty. Numbness in the lower-extremity is a common symptom in older adults with a variety of causes [22] and a classic symptom of peripheral neuropathy [23]. Numbness has been associated with nerve or nerve root injury as well as inhibition of the tactile process by nociceptive stimuli [24]. This inhibition may interfere with the swallowing process, starting with an increase in saliva production, formation of the bolus, ejection of the food bolus until the onset of peristalsis. Of the reflexes present in swallowing, tactile sensitivity is extremely important.

Recently, a study revealed that clinical changes in the oral sensorimotor system and non-functional oral status (with tooth loss and edentulous) are associated with a higher prevalence of oropharyngeal dysphagia in older persons who do not have swallowing complaints [25]. From the clinical evaluation of anatomical structures and orofacial functionality, which indicates the normality of the encephalic nerves, it was observed that altered function (mobility, strength, sensitivity and phonation) in any 4 or more of the following oral components, including lips (mobility and sensitivity), tongue (mobility, strength and sensitivity), soft palate (mobility and sensitivity), jaw (mobility) and larynx (phonation and mobility), is detrimental to swallowing [25]. Another recent study found that older persons show decline in the sensory function of the pharynx, assessed by electroencephalography and concluded that this sensory impairment may be a critical pathophysiological element detrimental to oral functions and should be viewed as a potential treatment target for swallowing impairment in older patients [26]. These studies are supportive of the longitudinal findings of the present study.

Previous studies from the Health ABC Study indicate that over half of mobility-intact older adults in this cohort have lower extremity sensorimotor peripheral nerve impairments [27] and these impairments are associated with a twofold increase in incident mobility limitations. Additionally, poor sensorimotor peripheral nerve function is related to slower endurance walking and greater slowing longitudinally [28]. A recent study indicated that there is an association with indicators of cardiovascular autonomic function and sensorimotor peripheral nerve impairments [29]. The current study adds to these findings in demonstrating a greater risk of swallowing difficulties in older persons with sensorimotor peripheral nerve impairments.

The cortical neuroplastic mechanisms and processes underlying orofacial sensory and motor functions may be important for the development of new therapeutic strategies to facilitate the recovery of patients with orofacial pain and sensorimotor disorders, as well as to improve their quality of life [30]. The results of the present study support the development of interventions for early identification and treatment 
Table 1 Proportion of swallowing impairment by sociodemographics (block 1), lifestyle factors (block 2), oral health status (block 3), health status (block 4) and sensorimotor peripheral nerve function (block 5) variables $(n=607)$

\begin{tabular}{|c|c|c|c|}
\hline Variable & $\begin{array}{l}\text { Normal } \\
\text { Swallowing } \\
n=499\end{array}$ & $\begin{array}{l}\text { Swallowing } \\
\text { Impairment } \\
n=108\end{array}$ & $p$ value* \\
\hline \multicolumn{4}{|l|}{ Block 1} \\
\hline Age & $75.81 \pm 2.67^{\mathrm{a}}$ & $75.66 \pm 2.68^{\mathrm{a}}$ & 0.707 \\
\hline \multicolumn{4}{|l|}{ Race } \\
\hline White & $338(67.7 \%)$ & $73(67.6 \%)$ & 0.530 \\
\hline \multicolumn{4}{|l|}{ Sex } \\
\hline Male & $213(42.7 \%)$ & $55(50.9 \%)$ & 0.118 \\
\hline \multicolumn{4}{|l|}{ Education } \\
\hline HS diploma & $202(40.6 \%)$ & $48(44.4 \%)$ & 0.209 \\
\hline HS diploma/equivalent or above & $296(59.4 \%)$ & $60(55.6 \%)$ & \\
\hline \multicolumn{4}{|l|}{ Income } \\
\hline$>\$ 50,000$ & $164(61.7 \%)$ & $40(74.1 \%)$ & 0.056 \\
\hline \multicolumn{4}{|l|}{ Site-state } \\
\hline Memphis & $215(43.1 \%)$ & $66(61.1 \%)$ & $<0.001$ \\
\hline \multicolumn{4}{|l|}{ Block 2} \\
\hline \multicolumn{4}{|l|}{ Marital status } \\
\hline Single/divorced/widowed & $288(57.8 \%)$ & $73(67.6 \%)$ & 0.061 \\
\hline \multicolumn{4}{|l|}{ Smoking status } \\
\hline Never smoker & $254(50.8 \%)$ & $43(39.8 \%)$ & 0.106 \\
\hline Current smoker & $31(6.2 \%)$ & $7(6.5 \%)$ & \\
\hline Former smoker & $214(43.0 \%)$ & $58(53.7 \%)$ & \\
\hline \multicolumn{4}{|l|}{ Drinking status } \\
\hline Never drinking & $129(26.0 \%)$ & $28(26.2 \%)$ & 0.016 \\
\hline Current drinking & $293(59.0 \%)$ & $51(47.7 \%)$ & \\
\hline Former drinking & $75(15.0 \%)$ & $28(26.2 \%)$ & \\
\hline Physical activity & $60.41(37.73-100.51)^{\mathrm{c}}$ & $66.51(38.40-105.70)^{\mathrm{c}}$ & $0.475^{\mathrm{d}}$ \\
\hline \multicolumn{4}{|l|}{ Block 3} \\
\hline \multicolumn{4}{|l|}{ Number of teeth } \\
\hline None & $35(7.0 \%)$ & $5(4.6 \%)$ & 0.653 \\
\hline $1-20$ & $284(56.9 \%)$ & $64(59.3 \%)$ & \\
\hline+20 & $180(36.1 \%)$ & $39(36.1 \%)$ & \\
\hline Total number of functional tooth units & $6.83 \pm 5.02^{\mathrm{a}}$ & $5.88 \pm 5.04^{\mathrm{a}}$ & 0.671 \\
\hline \multicolumn{4}{|l|}{ Wear dentures } \\
\hline Yes & $175(53.5 \%)$ & $37(56.1 \%)$ & 0.405 \\
\hline \multicolumn{4}{|l|}{ Block 4} \\
\hline \multicolumn{4}{|l|}{ Health status } \\
\hline Fair and poor & $37(7.7 \%)$ & $21(19.6 \%)$ & $<0.001$ \\
\hline \multicolumn{4}{|l|}{ Stroke } \\
\hline Yes & $28(5.6 \%)$ & $21(19.4 \%)$ & 0.042 \\
\hline \multicolumn{4}{|l|}{ Pneumonia } \\
\hline Yes & $21(4.2 \%)$ & $11(10.2 \%)$ & 0.637 \\
\hline \multicolumn{4}{|l|}{ Hypertension } \\
\hline Yes & $43(8.6 \%)$ & $16(14.8 \%)$ & 0.042 \\
\hline \multicolumn{4}{|l|}{ Heart attack/angina } \\
\hline Yes & $57(11.4 \%)$ & $14(12.9 \%)$ & 0.022 \\
\hline \multicolumn{4}{|l|}{ Any fracture } \\
\hline Yes & $48(9.6 \%)$ & $15(13.8 \%)$ & 0.338 \\
\hline
\end{tabular}


Table 1 (continued)

\begin{tabular}{|c|c|c|c|}
\hline Variable & $\begin{array}{l}\text { Normal } \\
\text { Swallowing } \\
n=499\end{array}$ & $\begin{array}{l}\text { Swallowing } \\
\text { Impairment } \\
n=108\end{array}$ & $p$ value* \\
\hline \multicolumn{4}{|l|}{ Diabetes } \\
\hline Yes & $93(18.6 \%)$ & $18(16.6 \%)$ & 0.206 \\
\hline \multicolumn{4}{|l|}{ Cancer } \\
\hline Yes & $53(10.6 \%)$ & $15(13.8 \%)$ & 0.003 \\
\hline \multicolumn{4}{|l|}{ Depressed } \\
\hline Yes & $68(13.6 \%)$ & $16(14.8 \%)$ & 0.094 \\
\hline Health $\mathrm{ABC}$ physical performance battery score & $2.44 \pm 0.44^{\mathrm{a}}$ & $2.45 \pm 0.47^{\mathrm{a}}$ & $0.310^{\mathrm{b}}$ \\
\hline \multicolumn{4}{|c|}{ Block 5-Peripheral nerve symptoms and impairments in the legs and feet } \\
\hline \multicolumn{4}{|l|}{ Numbness } \\
\hline Yes & $186(37.7 \%)$ & $73(68.2 \%)$ & $<0.001$ \\
\hline \multicolumn{4}{|l|}{ Pain } \\
\hline Yes & $110(22.1 \%)$ & $44(41.5 \%)$ & $<0.001$ \\
\hline \multicolumn{4}{|l|}{ Open sore or gangrene } \\
\hline Yes & $16(3.2 \%)$ & $1(0.9 \%)$ & 0.165 \\
\hline \multicolumn{4}{|l|}{ Poor amplitude $(<1 \mathrm{mV})$} \\
\hline Yes & $85(17.0 \%)$ & $18(16.7 \%)$ & 0.528 \\
\hline \multicolumn{4}{|l|}{ Poor velocity $(<40 \mathrm{~m} / \mathrm{s})$} \\
\hline Yes & $171(34.3 \%)$ & $47(43.5 \%)$ & 0.045 \\
\hline \multicolumn{4}{|l|}{ Poor vibration $(>130 \mu \mathrm{m})$} \\
\hline Yes & $62(13.1 \%)$ & $14(13.6 \%)$ & 0.475 \\
\hline
\end{tabular}

*Chi-square

${ }^{\mathrm{a}}$ Mean \pm standard deviation

${ }^{\mathrm{b}}$ Student's $t$ test

${ }^{\mathrm{c}} \operatorname{Median}(1$ quartile-3 quartile)

${ }^{\mathrm{d}}$ Wilcoxon-Mann-Whitney

of swallowing problems in community dwelling older adults with symptoms or signs of peripheral nerve impairment.

This study has some limitations that should be considered. The outcome was based on self-perceived symptoms, which may have underestimated the results, since older people rarely present complaints related to changes in swallowing, even though it is a frequent clinical finding in this population [7]. Nevertheless, since occurrences of swallowing impairment may be even higher than reported, the associations we found may be weaker than the true associations. Further studies with diverse populations, including those from other countries with different levels of development and with different socio-demographic backgrounds, should be conducted.

The clinical and epidemiological importance of this study is its potential contribution of evidence for professionals who care for older adults to attend to possible predictors of swallowing difficulties to minimize clinical complications such as malnutrition, dehydration, aspiration pneumonia and associated mortality $[8,9]$. This work also shows that relatively simple measures such as ascertaining feelings of numbness may help identify older adults with swallowing impairments.

\section{Conclusion}

This study demonstrates that initial motor nerve conduction velocity impairments and symptoms of numbness in the legs or feet are associated with a higher likelihood of swallowing difficulties at decade later in older adults. Early diagnosis, as well as guidance and care strategies should be incorporated by health care professionals, to help alleviate the impact of changes in swallowing and its consequences. 
Table 2 Crude and adjusted odds ratios of swallowing impairment by sensorimotor peripheral nerve impairment in the older persons $(n=607)$

\begin{tabular}{|c|c|c|c|c|c|c|}
\hline Variable & OR crude (CI95\%) & $p$ value & OR adjusted (CI95\%) & $p$ value & OR adjusted $^{\mathrm{a}, \mathrm{b}}(\mathrm{CI} 95 \%)$ & $p$ value \\
\hline \multicolumn{7}{|c|}{ Numbness } \\
\hline No & 1 & - & 1 & - & 1 & - \\
\hline Yes & $2.45(1.77-3.39)$ & $<0.001$ & $3.35(2.05-5.47)$ & $<0.001$ & $4.67(2.24-9.75)$ & $<0.001$ \\
\hline \multicolumn{7}{|l|}{ Pain } \\
\hline No & 1 & - & 1 & - & 1 & - \\
\hline Yes & $2.45(1.77-3.41)$ & $<0.001$ & $1.87(1.15-3.04)$ & 0.011 & $1.39(0.64-3.05)$ & 0.405 \\
\hline \multicolumn{7}{|c|}{ Open sore or gangrene } \\
\hline No & 1 & - & 1 & - & 1 & - \\
\hline Yes & $0.50(0.15-1.70)$ & 0.269 & $0.26(0.03-2.10)$ & 0.206 & $0.56(0.06-5.51)$ & 0.622 \\
\hline \multicolumn{7}{|c|}{ Poor amplitude $(<1 \mathrm{mV})$} \\
\hline No & 1 & - & 1 & - & 1 & - \\
\hline Yes & $1.05(0.64-1.75)$ & 0.834 & $0.80(0.42-1.51)$ & 0.495 & $0.70(0.28-1.77)$ & 0.454 \\
\hline \multicolumn{7}{|c|}{ Poor velocity $(<40 \mathrm{~m} / \mathrm{s})$} \\
\hline No & 1 & - & 1 & - & 1 & - \\
\hline Yes & $1.48(0.97-2.26)$ & 0.070 & $1.65(1.02-2.66)$ & 0.040 & $2.26(1.08-4.70)$ & 0.030 \\
\hline \multicolumn{7}{|c|}{ Poor vibration $(>130 \mu \mathrm{m})$} \\
\hline No & 1 & - & 1 & - & 1 & - \\
\hline Yes & $1.04(0.65-1.66)$ & 0.868 & $0.72(0.36-1.43)$ & 0.350 & $0.40(0.14-1.11)$ & 0.079 \\
\hline
\end{tabular}

${ }^{\mathrm{a}}$ Adjusted model of block 5 by block 1 and block 4

${ }^{\mathrm{b}}$ Final model

Acknowledgements This work was supported by the Intramural Research Program of the NIH, National Institute on Aging and for Brazilian Ministry of Education; National Council for Scientific and Technological Development-CNPq. JBH, FNH and BNGG hold productivity fellowship from CNPq.

Funding This research was supported in part by the Intramural Research Program of the NIH, National Institute on Aging. This research was supported by National Institute on Aging (NIA) Contracts \#N01-AG-6-2101; N01-AG-6-2103; N01-AG-6-2106; NIA Grant R01-AG028050; NINR Grant R01-NR012459.

\section{Compliance with ethical standards}

Conflict of interest The authors declare that they have no conflict of interest.

Statement of human and animal rights Protocols were approved by institutional review boards at the University of Pittsburgh and University of Tennessee Health Science Center. One project has been approved by Health $\mathrm{ABC}$ for use of secondary data.

Informed consent All participants provided written informed consent before participating.

\section{References:s}

1. Hamdy S, Mistry S (2008) Neural control of feeding and swallowing. Phys Med Rehabil Clin N Am 19:709-728. https://doi. org/10.1016/j.pmr.2008.05.002
2. Martin RE, Sessle BJ (1993) The role of the cerebral cortex in swallowing. Dysphagia 8:195-202. https://doi.org/10.1007/bf013 54538

3. Diamant NE (1996) Firing up the swallowing mechanism. Nat Med 2:1190-1191. https://doi.org/10.1038/nm1196-1190

4. Ertekin C, Aydogdu I (2003) Neurophysiology of swallowing. Clin Neurophysiol 114:2226-2244. https://doi.org/10.1016/S1388 -2457(03)00237-2

5. Alagiakrishnan K, Bhanji RA, Kurian M (2013) Evaluation and management of oropharyngeal dysphagia in different types of dementia: a systematic review. Arch Gerontol Geriatr 56:1-9. https://doi.org/10.1016/j.archger.2012.04.011

6. Wilson RD (2012) Mortality and cost of pneumonia after stroke for different risk groups. J Stroke Cerebrovasc Dis 21:61-67. https ://doi.org/10.1016/j.jstrokecerebrovasdis.2010.05.002

7. Achem SR, Devault KR (2005) Dysphagia in aging. J Clin Gastroenterol 39:357-371. https://doi.org/10.1097/01.mcg.0000159272 .88974 .54

8. Martino R, Foley N, Bhogal S et al (2005) Dysphagia after stroke incidence, diagnosis, and pulmonary complications. Stroke 36:2756-2763. https://doi.org/10.1161/01.STR.0000190056 $.76543 . \mathrm{eb}$

9. Ney DM, Weiss JM, Kind AJ et al (2009) Senescent swallowing: impact, strategies, and interventions. Nutr Clin Pract 24:395-413. https://doi.org/10.1177/0884533609332005

10. Cowen T, Ulfhake B, King R (2005) Aging in the peripheral nervous system. In: Dyck P, Thomas P (eds) Peripheral neuropathy, vol 1, 4th edn. Elsevier Saunders, Philadelphia

11. Verdú E, Ceballos D, Vilches J et al (2000) Influence of aging on peripheral nerve function and regeneration. J Peripher Nerv Syst 5:191-208. https://doi.org/10.1111/j.1529-8027.2000.00026.x 
12. Health ABC Study (2019) The dynamics of health, aging, and body composition. https://healthabc.nia.nih.gov/. Accessed 01 Dec 2019

13. Ward RE, Boudreau RM, Vinik AI et al (2013) Reproducibility of peroneal motor nerve conduction measurement in older adults. Clin Neurophysiol 124:603-609. https://doi.org/10.1016/j.clinp h.2012.07.027

14. Maser RE, Viggo K, Dorman JS et al (1991) Measuring subclinical neuropathy: does it relate to clinical neuropathy? Pittsburgh epidemiology of diabetes study-V. J Diabet Complicat 5:6-12. https://doi.org/10.1016/0891-6632(91)90003-8

15. Radloff L (1977) The CES-D scale: a self-report depression scale for research in the general population. Appl Psychol Meas 1:385401. https://doi.org/10.1177/014662167700100306

16. Simonsick EM, Newman AB, Nevitt MC et al (2001) Measuring higher level physical function in well-functioning older adults: expanding familiar approaches in the Health $\mathrm{ABC}$ study. J Gerontol A 56:M644-M649. https://doi.org/10.1093/gerona/56.10. $\mathrm{m} 644$

17. Victora CG, Huttly SR, Fuchs SC, Olinto MT (1997) The role of conceptual frameworks in epidemiological analysis: a hierarchical approach. Int J Epidemiol 26:224-227. https://doi.org/10.1093/ ije/26.1.224

18. Ahmed T, Haboubi N (2010) Assessment and management of nutrition in older people and its importance to health. Clin Interv Aging 5:207-216

19. Mistry S, Hamdy S (2008) Neural control of feeding and swallowing. Phys Med Rehabil Clin N Am 19:709-728. https://doi. org/10.1016/j.pmr.2008.05.002

20. Sasegbon A, Hamdy S (2017) The anatomy and physiology of normal and abnormal swallowing in oropharyngeal dysphagia. Neurogastroenterol Motil. https://doi.org/10.1111/nmo.13100

21. Jean A (2001) Brain stem control of swallowing: neuronal network and cellular mechanisms. Physiol Rev 31:929-969. https://doi. org/10.1152/physrev.2001.81.2.929

22. Windebank AJ, Grisold W (2008) Chemotherapy-induced neuropathy. J Peripher Nerv Syst 13:27-46. https://doi.org/10.111 1/j.1529-8027.2008.00156.x
23. Liu H, Tan AD, Grothey A et al (2008) Comparing and validating simple measures of patient-reported peripheral neuropathy (PRPN) for NCCTG Clinical Trials: a pooled analysis of 2,440 patients (pts). J Clin Oncol 26:9534. https://doi.org/10.1200/ jco.2008.26.15_suppl.9534

24. Geber C, Magerl W, Fondel R et al (2008) Numbness in clinical and experimental pain-a cross-sectional study exploring the mechanisms of reduced tactile function. Pain 139:73-81. https:// doi.org/10.1016/j.pain.2008.03.006

25. Rech RS, Baumgarten A, Colvara BC et al (2018) Association between oropharyngeal dysphagia, oral functionality, and oral sensorimotor alteration. Oral Dis 24:664-672. https://doi. org/10.1111/odi.12809

26. Rofes L, Ortega O, Vilardell N, Mundet L, Clavé P (2017) Spatiotemporal characteristics of the pharyngeal event-related potential in healthy subjects and older patients with oropharyngeal dysfunction. Neurogastroenterol Motil. https://doi.org/10.1111/ nmo. 12916

27. Ward RE, Boudreau RM, Caserotti P et al (2014) Sensory and motor peripheral nerve function and incident mobility disability. J Am Geriatr Soc 62:2273-2279

28. Lange-Maia BS, Newman AB, Cauley JA et al (2016) Sensorimotor peripheral nerve function and the longitudinal relationship with endurance walking in the health, aging, and body composition study. Arch Phys Med Rehabil 97:45-52. https://doi. org/10.1111/jgs. 13152

29. Lange-Maia BS, Newman AB, Jakicic JN et al (2017) Relationship between sensorimotor peripheral nerve function and indicators of cardiovascular autonomic function in older adults from the Health, Aging and Body Composition Study. Exp Gerontol 96:38-45. https://doi.org/10.1016/j.exger.2017.04.007

30. Avivi-Arber L, Lee J, Yao D et al (2010) Neuroplasticity of face sensorimotor cortex and implications for control of orofacial movements. Jpn Dent Sci Rev 46:132-142. https://doi. org/10.1016/j.jdsr.2009.11.007

Publisher's Note Springer Nature remains neutral with regard to jurisdictional claims in published maps and institutional affiliations. 